\title{
Effect of hamstring injuries on kicking in soccer using inverse dynamics
}

Premio SIBB 2013

\author{
A. NAVANDAR ${ }^{1}$, M. GULINO ${ }^{2}$, R. ANTONIO ${ }^{1}$, E. NAVARRO ${ }^{1}$ \\ ${ }^{1}$ Faculty of Physical Activity and Sport Sciences. Technical University of Madrid \\ ${ }^{2}$ Biomedical Engineering Department. Politecnico di Torino
}

\begin{abstract}
Resumen
Las lesiones musculares del muslo tienen una gran incidencia en el fútbol. El objetivo del estudio ha sido desarrollar un nuevo procedimiento para evaluar el efecto de las lesiones de isquiotibiales en los golpeos con el pie s en el fútbol utilizando los principios de la dinámica inversa. El trabajo se ha centrado en la evaluación de la diferencia entre sujetos que habían sufrido la lesión en los últimos 5 años y los que no. Se analizaron 17 jugadores de fútbol profesionales realizando cinco tiros con el empeine y cinco con el interior del pie. Los movimientos se registraron mediante una plataforma de fuerza y un sistema de captura de movimiento Vicon funcionando a $500 \mathrm{~Hz}$. Los participantes también tomaron parte en una prueba de isocinético en la que se midió el torque isocinético en $60 \%$ s y 120 $\%$ s. Se observaron diferencias significativas en los parámetros cinemáticos y cinéticos entre los dos grupos (lesionados y no lesionados) en la fase posterior del golpeo y en el instante de máxima flexión de cadera. No se encontraron diferencias significativas entre los dos grupos en la prueba isocinética tradicional. Estos resultados indican que el procedimiento empleado probablemente podría ser muy útil en la evaluación del efecto de las lesiones de isquiotibiales en el fútbol.
\end{abstract}

Palabras clave: Biomecánica, chut, lesiones de isquiotibiales, cinética, cinemática.

\begin{abstract}
The hamstring strain is one of the most common injuries in soccer. The aim of the study was to describe a new procedure to evaluate the effect of hamstring injuries in kicking in soccer using the principles of inverse dynamics and to compare the results with an isokinetic test. The study focused on evaluating the difference between subjects having a history of hamstring injuries in the last 5 years and those that did not. Seventeen male professional soccer players performed five instep and sidefoot kicks which were analysed using a force platform and a Vicon motion-capture system operating at $500 \mathrm{~Hz}$. The participants also took part in an isokinetic torque measurement at $60 \% \mathrm{~s}$ and $120 \% \mathrm{~s}$. Kinematic variables, ground reaction forces and kinetic variables were compared across the two groups. Significant differences were observed between the previously injured and uninjured group in the time taken for the follow through in the instep kick, and the maximum hip flexion moment in the instep and side-foot kicks. No significant differences were found between the two groups in the traditional isokinetic test. These results indicate that the procedure employed could probably be very useful in the assessment of the effect of hamstring injuries in soccer.
\end{abstract}

Keywords: Biomechanics, kicking, hamstring injuries, kinetics, kinematics.

Correspondencia:

Archit Navandar

Laboratorio Biomecánica

Facultad de Ciencias de la Actividad Física y del Deporte-INEF

Universidad Politécnica de Madrid.

C/ Martín Fierro 7, 28040 Madrid, España.

Email: archit.navandar@alumnos.upm.es. 


\section{Introduction}

Soccer injuries have been ranked first among other sports with a rate ranging from 3.7 to 29.1 injuries per 1000 hours of practice and games [13]. Approximately $60-80 \%$ of soccer injuries occur at the lower extremities [13]. One of the most common injuries in nearly all forms of team and individual sports involving the lower body is the hamstring strain $[4,7,10]$.

An analysis of epidemiological injury studies assessing these sports consistently ranks hamstring strain injuries as one of the most prevalent factors resulting in missed playing time by football players [17]. A ten year study on European soccer found that one third of all injuries in professional soccer are muscle injuries (31\% of all injuries and caused $27 \%$ of the total injury absence); and injuries to the hamstrings contributing to $37 \%$ of them [8]. In a study of English professional soccer athletes, the thigh was the most prevalent site for injury, with $81 \%$ of thigh injuries classified as muscular strains [10]. On an average, 18 days and 3-3.5 matches are missed per hamstring strain in a soccer player [22]. Apart from the playing and training time lost by the affected players, these injuries add up to being a financial burden on the clubs [9].

Studies indicate that hamstring muscle strains most commonly occur during the latter part of the swing phase, when the hamstrings work to decelerate knee extension in preparation for heel strike $[15,22]$. The muscle fibres are rapidly lengthened when they change from functioning eccentrically, to decelerate knee extension in the late swing, to concentrically, in becoming an active extensor of the hip joint. It has been suggested that it is during this rapid change from eccentric to concentric increases the susceptibility of the hamstrings to injury as a result of the biomechanical loads placed on the muscle $[4,22]$. Considering that most athletes injure their hamstrings while running/ sprinting, an association may exist between hip and knee biomechanical anomalies in running and an increased risk of injury/re-injury [15]. Such anomalies might exist in the kicking pattern as well, and to our knowledge, this has not been investigated as yet.

One of the most common methods of evaluating hamstring injuries in soccer has been using isokinetic torque measurements. These tests require the subjects to be seated, lying down or standing depending on the type of test carried out. Although the forces and moments are quantified, these tests are far different from the actions that professional soccer players go through on a regular basis. Thus a test that mimics the movements that professional soccer players undergo on a regular basis could identify the impact of the hamstring injury on the kicking skills of a soccer player.

Thus the objectives of our study were threefold: firstly to develop a new procedure to evaluate the effect of the hamstring injuries on the kicking skills in soccer players; secondly, to investigate the difference between the biomechanical kicking pattern between soccer players with a previous history of hamstring injuries and those without one; and thirdly, to compare the results with tests on hamstring strength using isokinetic testing methods. We chose to analyse the two kicking skills most prominent in soccer: the instep and the side-foot kicks. The instep kick, the prime objective of which is speed, is frequently used in long-distance shooting or passing $[11,18]$. In contrast, the side-foot kick, the main objective of which is accuracy, is used for shorter shots and passes $[11,18]$. Our hypothesis was that there exists a difference in the biomechanical kicking pattern between athletes with a previous history of hamstring injury and those without.

\section{Methods}

\section{Participants}

Seventeen male professional soccer players volunteered to take part in the study (average age $23.41 \pm 4.24$ years; weight $=75.58 \pm 7.99 \mathrm{~kg}$; height $=178.66 \pm 5.79 \mathrm{~cm}$ ). Players were selected such that they were playing in the same division with the number of training sessions and matches being the same for all players. The testing procedure was explained verbally to the players. All players provided written informed consent in accordance with the departmental and university ethical procedures and following the principles outlined in the Declaration of Helsinki. They took part in two sessions of testing that evaluated hamstring strength. Participants were asked about their injury history in the hamstrings in their dominant limb (defined as their "preferred kicking limb"), and those with a history within the last 5 years, but not less than 6 months were considered as "having a previous injury history" $(\mathrm{n}=4)$.

\section{Experimental Design}

The participants were required to take part in two sessions of data capture: the first involved motion capture of kicking and the second invol- 
ved isokinetic torque measurement. All participants were asked to wear indoor soccer shoes for the trials.

\section{Motion Capture}

A six-camera VICON motion capture system (Oxford Metrics Ltd., United Kingdom) was used to record data at $500 \mathrm{~Hz}$. An IBV Force Platform (Instituto de Biomecánica de Valencia, Spain) at $500 \mathrm{~Hz}$ was used to capture the ground reaction forces at the time of kicking and the two systems were synchronized using an electric trigger at the start of the trial. The system was calibrated in accordance with VICON guidelines, and yielded calibration residuals such that positional data accurate within $1 \mathrm{~mm}$ was obtained.

A lower body model was used to capture and analyse the data. Eighteen retro-reflective markers with a diameter of $14 \mathrm{~mm}$ were attached to the anatomical landmarks of each participant's body: the right and left anterior superior iliac spines, the right and left posterior superior iliac spines, the right and left medial and lateral epicondyle heads of the knee, the right and left lateral and medial malleoli, the right and left calcaneus, and the right and left heads of the second metatarsal. To identify the marker positions on the second metatarsal heads, the participants were asked to repeatedly lift and lower their hallux, and the point about which the movement of the toes was hinged along the second metatarsal was where the marker was placed. Markers were put approximately at the same height as those on the heads of the second metatarsal marker such that they were placed on the calcaneus: the difference in height between the markers on the calcaneus and metatarsal was noted. Markers were also placed laterally on the right and left thigh and shank to determine the alignment of the thigh and shank flexion axes [23]. A soccer ball officially approved by the International Football Federation (FIFA) was used. Two reflective markers were placed on the side of the ball to determine the timing of impact and the resultant ball velocity after the impact from the motion capture data.

Each participant performed a 20 minute warmup consisting of running and sprinting ( 8 minutes), aerobic and stretching exercises (6 minutes) and soccer-specific strength exercises (6 minutes). A static trial of the participant was captured, followed by a few kicks as a part of the warm up. The participant then performed 5 instep kicks and 5 side-foot kicks, such that the support leg at the time of kicking was placed on the platform. The participants were asked to take the kicks with their preferred kicking limb, with a two-step run up and asked to kick the ball as hard as possible at a net, $10 \mathrm{~m}$ away from the platform.

Hip joint centre was calculated based on the method suggested by Davis III et al [5], while the knee and ankle joint centres were calculated based on the algorithm defined in the VICON manual [23]. The kicking leg was modelled as a linksegment model composed of the foot, shank, and thigh. A local co-ordinate system was defined at each segment, such that the longitudinal axis was the $\mathrm{Z}$ (the positive direction being from the distal to proximal segment), the antero-posterior axis being $\mathrm{X}$, and $\mathrm{Y}$ being mutually perpendicular to both (such that the right hand rule was observed).

Inter-segmental angles were calculated using the Euler reference system. For all the local reference systems, flexion angle was defined as positive, while extension was defined as negative. A standard inverse-dynamics approach was used to calculate the forces and internal moments developed by the lower limb joints. Segmental inertial parameters were taken from de Leva [6]. All the calculations were carried out using the VICON BodyBuilder software (VICON; Oxford Metrics Ltd., United Kingdom). The orientations of the joint reaction moments were in accordance with the right hand rule, such that the moment of flexion at the hip and ankle was negative and the flexion moment at the knee was positive.

These calculations were done on unfiltered data as the impact of the foot with the ball is known to produce a sudden deceleration of the kicking leg, which causes a serious distortion of the kinetic data near impact when the data is filtered [19]. Using a procedure similar to Nunome et al [19] and Knudson and Bahamonde [14], data from all variables was eliminated 8 frames before and after ball impact, and the data was interpolated in this interval using splines. After interpolation all parameters were digitally smoothed by a fourth-order Butterworth filter at $12.5 \mathrm{~Hz}$.

The trial was divided into five characteristic time instances (Figure 1): toe-off of kicking leg (determined when the velocity of the toe marker on the kicking limb changed from 0 ) (TO), maximum extension of the hip (MHE), ball impact (BI), maximum flexion of the hip (MHF), and the end when the knee reached the maximum height $(\mathrm{MKH})$. The time intervals MHE-TO, BI-MHE and MHF-BI were defined as backswing, leg acceleration and follow-through respectively, and were normalized with respect to the total time interval MKH-TO. For analysis, only sagittal plane 
kinematic and kinetic variables of the kicking leg affected by the hamstring muscle (angle of hip flexion/extension, angle of knee flexion/extension, angular velocity of hip flexion/extension, and angular velocity of knee flexion/extension) were calculated at instances MHE, BI, and MHF. This is because hip and knee flexion/extension joint postures have the greatest influence on hamstring length [15].

The peak extension and flexion moments for the kicking leg were analysed. Peak flexion moment of the hip of kicking leg was assumed to coincide with the maximum extension of the hip (MHE) and computed at this instant. The instance of maximum hip extension moment was determined (THE), and its value calculated. The peak knee extension moment was determined. The knee moment was also calculated at ball impact and the peak flexion moment of the knee was assumed to coincide with THE. Peak ground reaction forces were also evaluated. All the kinetic variables determined were normalized in function with the body mass of the participant, so as to negate the impact of body mass in the calculations.

\section{Isokinetic torque measurement}

An isokinetic dynamometer (PRIMUSRS; BTE Technologies, USA) was used to measure the maximum voluntary concentric torque for the quadriceps and hamstrings at $60 \%$ s and $120 \%$ s. Prior to testing, the PRIMUSRS was calibrated by completing an automatic calibration process as set by the manufacturer. The participant performed a 10 minute warm-up prior to the testing consisting of aerobic and sprinting exercises. The isokinetic testing was done on the dominant limb in the seated position as described in the manual [3]. The lateral epicondyle of the knee of the dominant limb was visually aligned with the dynamometer's axis of rotation. Each participant's range of motion was set between $0^{\circ}$ and $90^{\circ}$ prior to testing with anatomical zero (full extension) set to $0^{\circ}$. A seat belt with upper body straps, along with a distal thigh strap were fitted to stabilize the participant in order to isolate the quadriceps and hamstrings of the dominant leg. At all times during the test the participants were required to cross their arms over their chest to minimize any support from the upper body. Ten warm-up trials were carried out at $180^{\circ} / \mathrm{s}$ to familiarize the participant with the testing procedure. This was followed by testing at $60 \% \mathrm{~s}$ and $120 \%$ s: three and five trials respectively (concentric hamstring and concentric quadriceps). A 90 second interval was allowed between velocities for the recovery of the subject. The maximum voluntary concentric hamstrings and quadriceps torque were selected amongst the trials for each speed. From the results obtained, the ratio of the concentric torque in hamstring to that in the quadriceps of the dominant limb was evaluated (H:Q ratio).

\section{Statistical Analyses}

All the variables mentioned above were statistically analysed. Non-parametric tests were

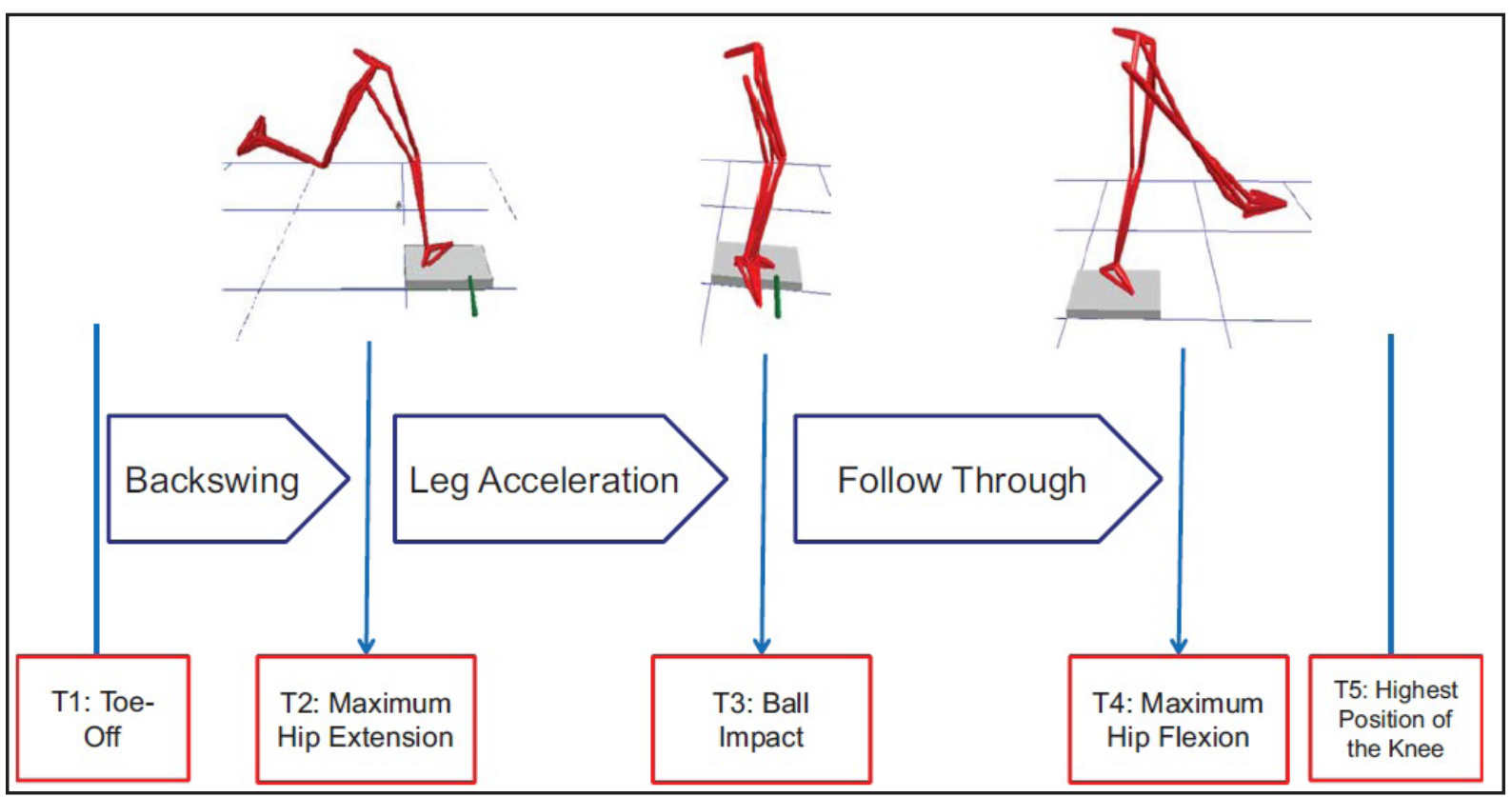

Figure 1. The phases of kicking and the characteristic time intervals. 
carried out on the dependent variables using the Statistical Package for Sports Sciences software (SPSS v15.0; Intel Software, USA). A confidence interval of $95 \%$ with $\alpha=0.05$ was assumed for all statistical analysis. The inter-subject differences between players with and without a history of hamstring injury were calculated using the MannWhitney U test.

\section{Results}

\section{Kinematics}

The pattern of kicking was found to be similar in both groups: the injured and the un-injured, and for both the types of kicks. A comparison of the different values of kinematic variables at the characteristic time instances is shown in Tables 1 and 2.

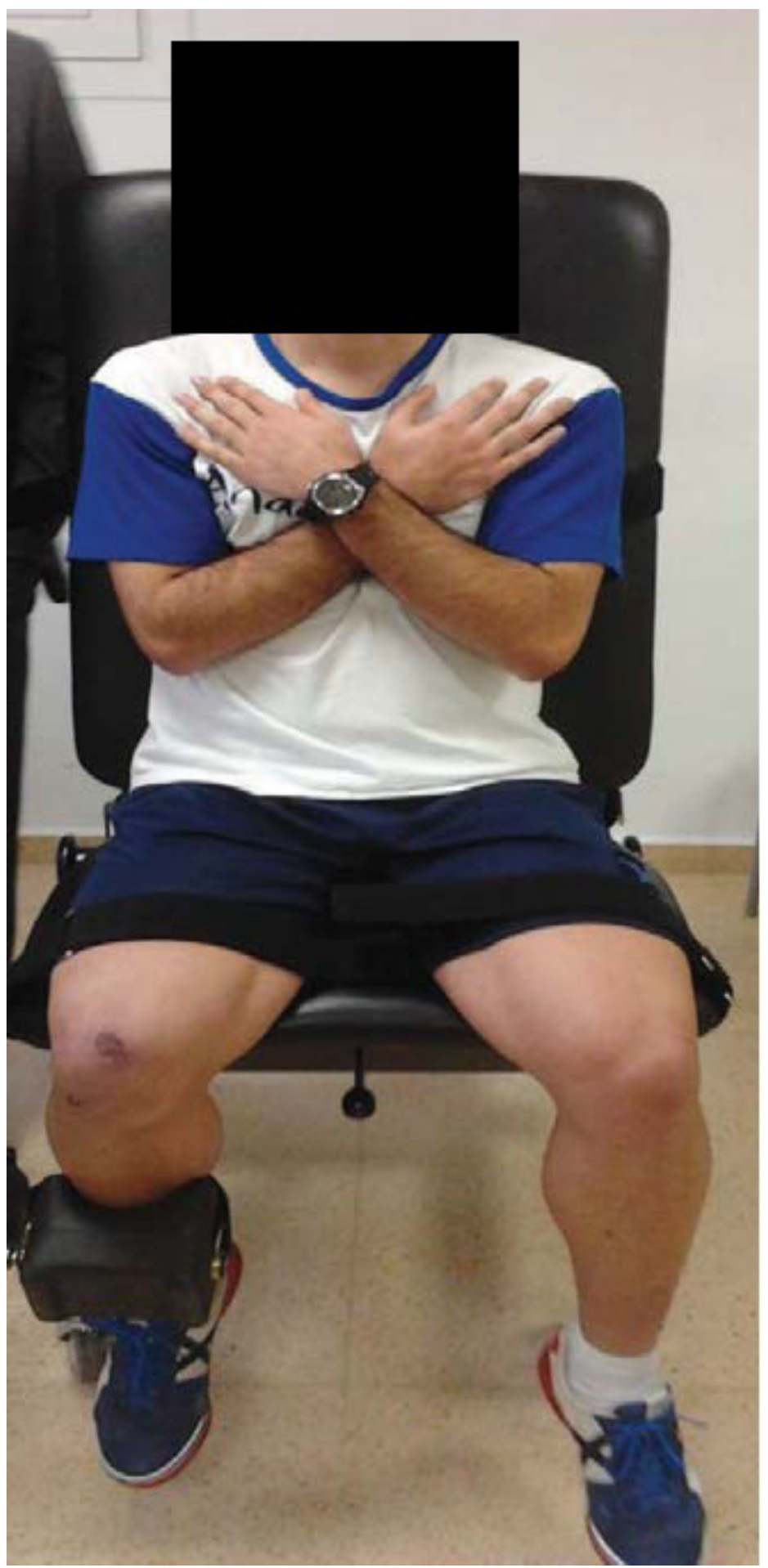

Figure 2. The isokinetic testing procedure. 
Figure 3 shows the changes in the hip and knee flexion-extension angles during the movement of the kicking limb during the soccer kick while Figure 4 shows the changes in the angular velocities of flexion-extension of the hip and knee during the same.

As seen from Tables 1 and 2, the difference between the participants with and without a history of hamstring injury in the kicking leg was found to be not-significant in the case of the above variables and ball velocities $(p>0.05)$.

The average normalized time for the back- swing, leg acceleration and follow through phases are shown in Tables 3 and 4. For the instep kicks, there was no significant difference found between the two groups for the hip extension and leg acceleration phases $(p>0.05)$. However, the time taken by the injured players $(39.41 \%)$ in the follow through phase was found to be significantly greater than in the un-injured group $(35.85 \%)$ with $\mathrm{Z}=2.06(\mathrm{p}=0.045)$. In the case of side-foot kicks, the average normalized time for the distinct phases of the kick was found to be not significant between the groups $(\mathrm{p}>0.05)$.

\begin{tabular}{|c|c|c|c|c|c|c|c|}
\hline & \multirow{2}{*}{$\begin{array}{l}\text { Ball Velocity } \\
\qquad(\mathrm{m} / \mathrm{s})\end{array}$} & \multicolumn{3}{|c|}{ Hip Angle (ㅇ) } & \multicolumn{3}{|c|}{ Knee Angle (ㅇ) } \\
\hline & & $\mathrm{T} 2$ & T3 & T4 & $\mathrm{T} 2$ & T3 & T4 \\
\hline Injured & $29.66 \pm 0.28$ & $-20.35 \pm 0.65$ & $17.97 \pm 6.23$ & $74.08 \pm 5.16$ & $\begin{array}{c}59.43 \pm \\
17.25\end{array}$ & $\begin{array}{c}41.27 \pm \\
17.82\end{array}$ & $\begin{array}{c}25.32 \pm \\
22.06\end{array}$ \\
\hline Un-injured & $28.93 \pm 2.12$ & $-20.55 \pm 7.55$ & $10.81 \pm 9.24$ & $\begin{array}{c}69.81 \pm \\
12.67\end{array}$ & $\begin{array}{c}59.75 \pm \\
17.57\end{array}$ & $\begin{array}{c}39.16 \pm \\
19.71\end{array}$ & $\begin{array}{c}26.72 \pm \\
29.08\end{array}$ \\
\hline Total & $29.10 \pm 1.87$ & $-20.50 \pm 6.55$ & $12.50 \pm 9.01$ & $\begin{array}{c}70.87 \pm \\
11.26\end{array}$ & $\begin{array}{c}59.68 \pm \\
16.95\end{array}$ & $\begin{array}{c}39.66 \pm \\
18.75\end{array}$ & $\begin{array}{c}26.37 \pm \\
26.79\end{array}$ \\
\hline Significance & 0.09 & 0.33 & 0.06 & 0.36 & 0.45 & 0.41 & 0.40 \\
\hline \multirow[t]{3}{*}{ Abs(r) } & 0.33 & 0.11 & 0.38 & 0.09 & 0.03 & 0.05 & 0.06 \\
\hline & Ball Velocity & \multicolumn{3}{|c|}{ Hip Angular Velocity (o/s) } & \multicolumn{3}{|c|}{ Knee Angular Velocity (ㅇ/s) } \\
\hline & $(\mathrm{m} / \mathrm{s})$ & $\mathrm{T} 2$ & T3 & T4 & $\mathrm{T} 2$ & T3 & T4 \\
\hline Injured & $29.66 \pm 0.28$ & $0.02 \pm 0.09$ & $-2.48 \pm 2.37$ & $0.18 \pm 0.17$ & $11.13 \pm 5.41$ & $-23.99 \pm 9.02$ & $4.75 \pm 6.73$ \\
\hline Un-injured & $28.93 \pm 2.12$ & $0.02 \pm 0.09$ & $-2.55 \pm 2.35$ & $0.53 \pm 1.56$ & $8.11 \pm 5.61$ & $-27.12 \pm 6.09$ & $3.51 \pm 3.83$ \\
\hline Total & $29.10 \pm 1.87$ & $0.02 \pm 0.09$ & $-2.53 \pm 2.28$ & $0.46 \pm 1.39$ & $8.82 \pm 5.55$ & $-26.39 \pm 6.71$ & $3.76 \pm 4.27$ \\
\hline Significance & 0.09 & 0.45 & 0.45 & 0.24 & 0.21 & 0.18 & 0.50 \\
\hline Abs $(r)$ & 0.33 & 0.03 & 0.03 & 0.18 & 0.19 & 0.22 & 0.00 \\
\hline
\end{tabular}

Table 1. Kinematic variables for the instep kick.

\begin{tabular}{|c|c|c|c|c|c|c|c|}
\hline & \multirow{2}{*}{$\begin{array}{l}\text { Ball Velocity } \\
\quad(\mathrm{m} / \mathrm{s})\end{array}$} & \multicolumn{3}{|c|}{ Hip Angle $\left({ }^{\circ}\right)$} & \multicolumn{3}{|c|}{ Knee Angle ( $\left(^{\circ}\right)$} \\
\hline & & $\mathrm{T} 2$ & T3 & T4 & $\mathrm{T} 2$ & T3 & T4 \\
\hline Injured & $26.32 \pm 1.60$ & $-17.15 \pm 2.97$ & $22.49 \pm 5.54$ & $67.39 \pm 11.10$ & $53.40 \pm 21.00$ & $38.72 \pm 25.05$ & $30.15 \pm 43.40$ \\
\hline Un-injured & $25.74 \pm 1.07$ & $-18.01 \pm 6.68$ & $18.73 \pm 11.03$ & $63.12 \pm 15.86$ & $53.31 \pm 20.06$ & $41.36 \pm 19.93$ & $19.96 \pm 26.05$ \\
\hline Total & $25.88 \pm 1.18$ & $-17.81 \pm 5.94$ & $19.61 \pm 9.98$ & $64.13 \pm 14.67$ & $53.33 \pm 19.61$ & $40.74 \pm 20.42$ & $22.50 \pm 29.92$ \\
\hline Significance & 0.21 & 0.50 & 0.18 & 0.33 & 0.41 & 0.37 & 0.36 \\
\hline \multirow[t]{3}{*}{$A b s(r)$} & 0.19 & 0.00 & 0.22 & 0.11 & 0.05 & 0.08 & 0.09 \\
\hline & Ball Velocity & \multicolumn{3}{|c|}{ Hip Angular Velocity $(\% / s)$} & \multicolumn{3}{|c|}{ Knee Angular Velocity ( $(\% / s)$} \\
\hline & $(\mathrm{m} / \mathrm{s})$ & $\mathrm{T} 2$ & $\mathrm{~T} 3$ & $\mathrm{~T} 2$ & T3 & $\mathrm{T} 2$ & T3 \\
\hline Injured & $26.32 \pm 1.60$ & $0.04 \pm 0.04$ & $-2.28 \pm 1.85$ & $0.04 \pm 0.04$ & $-2.28 \pm 1.85$ & $0.04 \pm 0.04$ & $-2.28 \pm 1.85$ \\
\hline Un-injured & $25.74 \pm 1.07$ & $0.00 \pm 0.07$ & $-2.47 \pm 1.74$ & $0.00 \pm 0.07$ & $-2.47 \pm 1.74$ & $0.00 \pm 0.07$ & $-2.47 \pm 1.74$ \\
\hline Total & $25.88 \pm 1.18$ & $0.01 \pm 0.06$ & $-2.43 \pm 1.71$ & $0.01 \pm 0.06$ & $-2.43 \pm 1.71$ & $0.01 \pm 0.06$ & $-2.43 \pm 1.71$ \\
\hline Significance & 0.21 & 0.11 & 0.45 & 0.11 & 0.45 & 0.11 & 0.45 \\
\hline$A b s(r)$ & 0.19 & 0.30 & 0.03 & 0.30 & 0.03 & 0.30 & 0.03 \\
\hline
\end{tabular}

Table 2. Kinematic variables for the side-foot kick. 


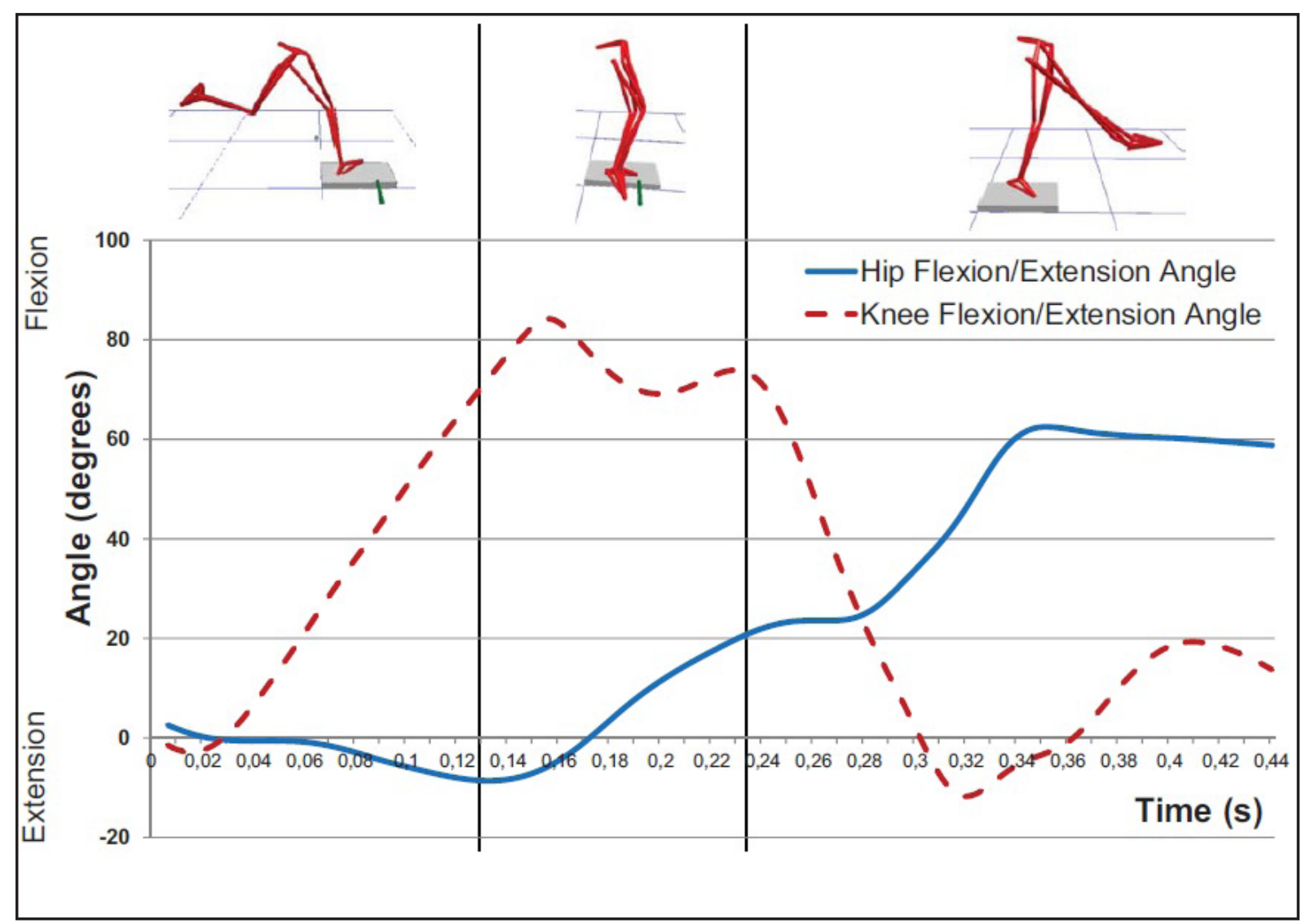

Figure 3. Variation of hip and knee flexion angle over time during an instep kick.

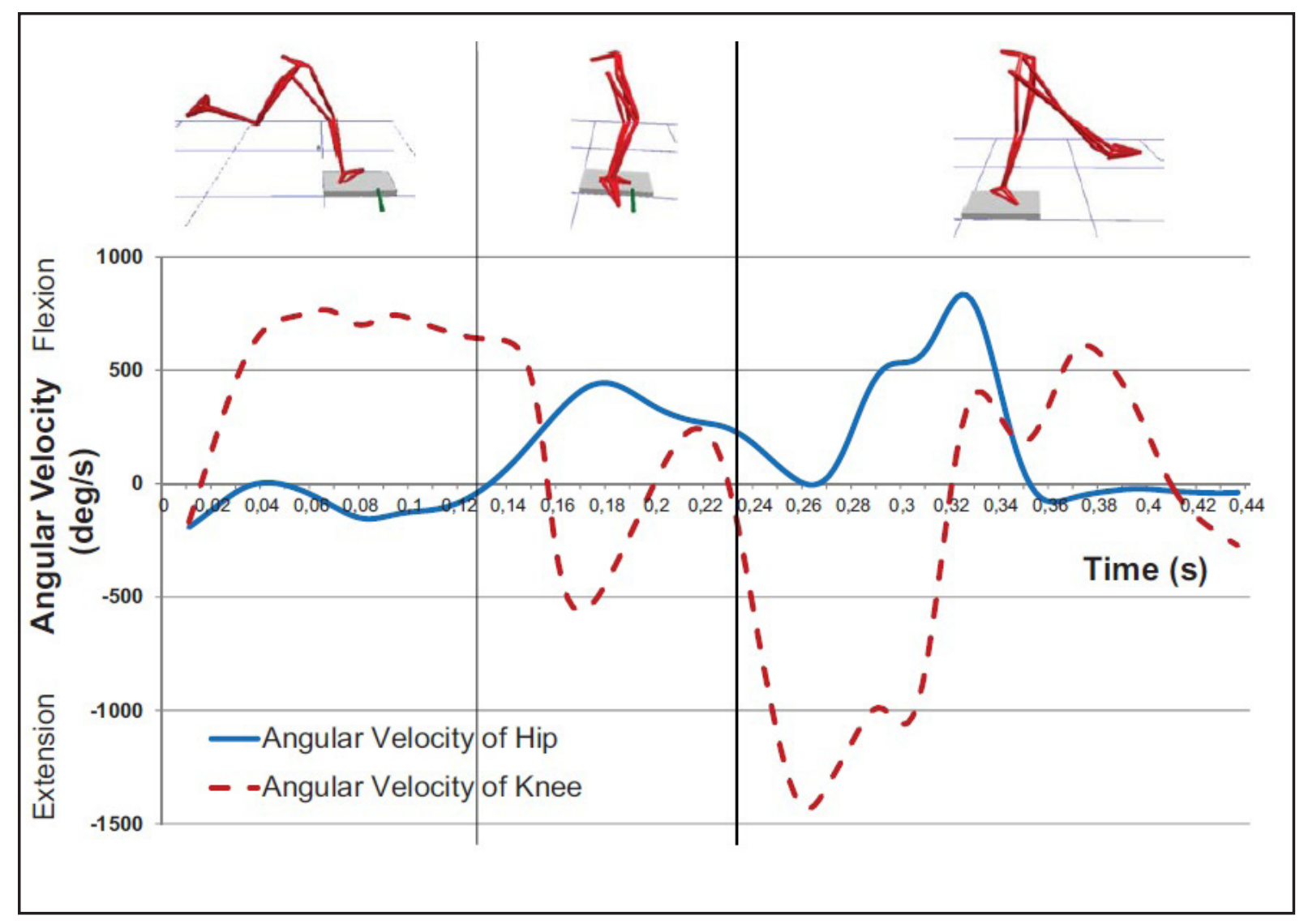

Figure 4. Variation of hip and knee flexion angular velocity over time during an instep kick. 


\section{Kinetics}

The kinetic patterns of the kicks were found to be similar across both the injured and the uninjured groups for both types of kicks. The hip and knee flexion-extension moments during the soccer kick are shown in Figures 5 and 6 respectively. The values of the different kinetic variables are shown in the Tables 5 and 6 .

\begin{tabular}{|c|c|c|c|}
\hline & Backswing (\%) & Leg Acceleration (\%) & Follow through (\%) \\
\hline Injured & $23.30 \pm 1.12(0.10 \mathrm{~s})$ & $28.44 \pm 1.83(0.12 \mathrm{~s})$ & $40.60 \pm 6.67(0.18 \mathrm{~s})$ \\
\hline Un-injured & $25.40 \pm 4.76(0.12 \mathrm{~s})$ & $28.95 \pm 3.21(0.13 \mathrm{~s})$ & $32.17 \pm 5.99(0.15 \mathrm{~s})$ \\
\hline Total & $24.90 \pm 4.25(0.11 \mathrm{~s})$ & $28.83 \pm 2.90(0.13 \mathrm{~s})$ & $34.28 \pm 7.03(0.16 \mathrm{~s})$ \\
\hline Significance & 0.04 & 0.37 & 0.02 \\
\hline Abs(r) & 0.41 & 0.08 & 0.50 \\
\hline
\end{tabular}

Table 3. Normalized temporal variables for the instep kick.

\begin{tabular}{|c|c|c|c|}
\hline & Backswing (\%) & Leg Acceleration (\%) & Follow through (\%) \\
\hline Injured & $22.62 \pm 4.36(0.10 \mathrm{~s})$ & $31.05 \pm 4.03(0.13 \mathrm{~s})$ & $39.41 \pm 3.57(0.17 \mathrm{~s})$ \\
\hline Un-injured & $24.40 \pm 6.73(0.10 \mathrm{~s})$ & $33.07 \pm 5.12(0.14 \mathrm{~s})$ & $35.84 \pm 5.89(0.15 \mathrm{~s})$ \\
\hline Total & $23.98 \pm 6.17(0.10 \mathrm{~s})$ & $32.59 \pm 4.85(0.14 \mathrm{~s})$ & $36.68 \pm 5.55(0.16 \mathrm{~s})$ \\
\hline Significance & 0.13 & 0.25 & 0.11 \\
\hline Abs(r) & 0.27 & 0.16 & 0.30 \\
\hline
\end{tabular}

Table 4. Normalized temporal variables for the side-foot kick.

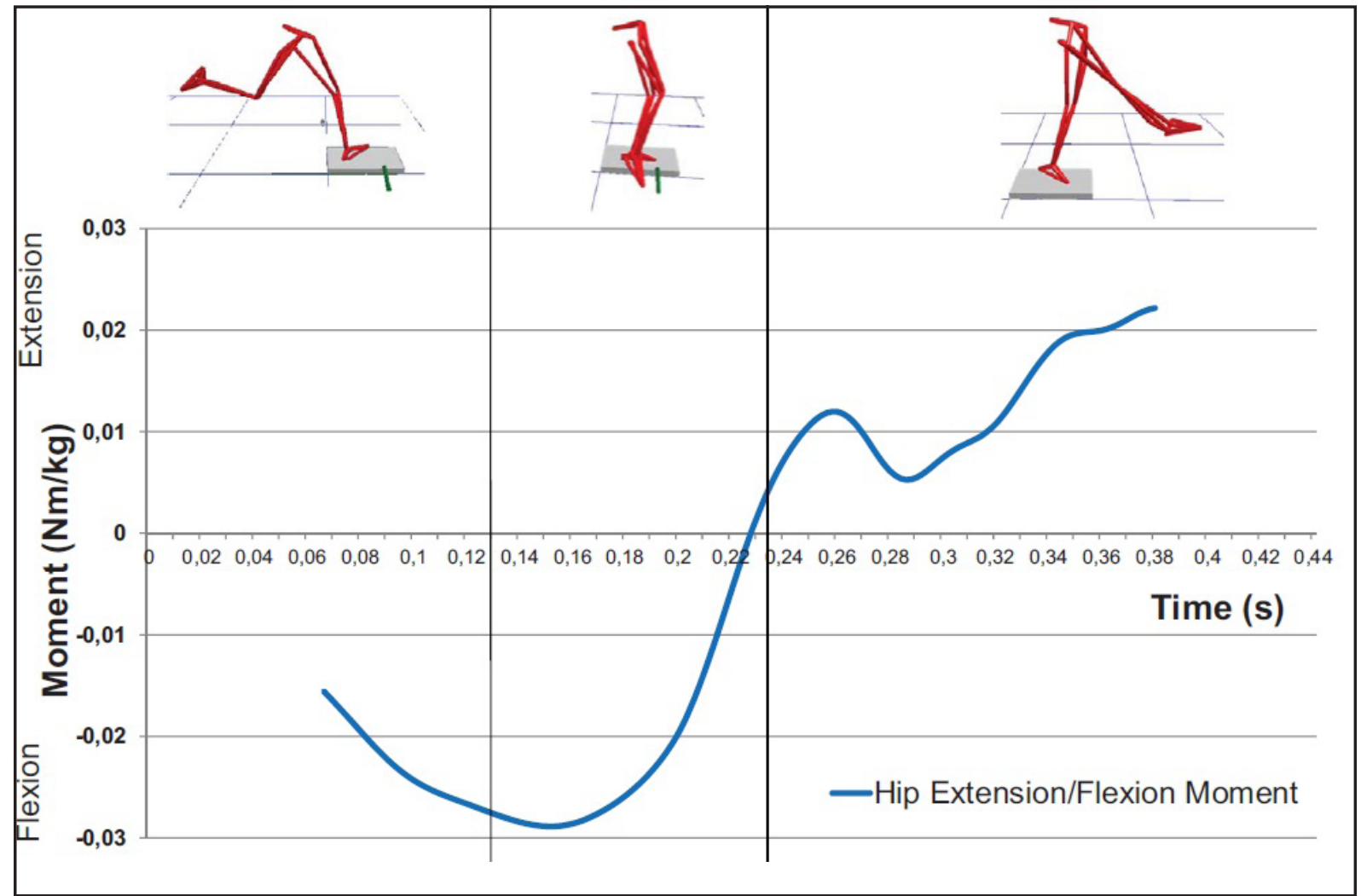

Figure 5. Variation of instep hip extension/flexion moment over time. 


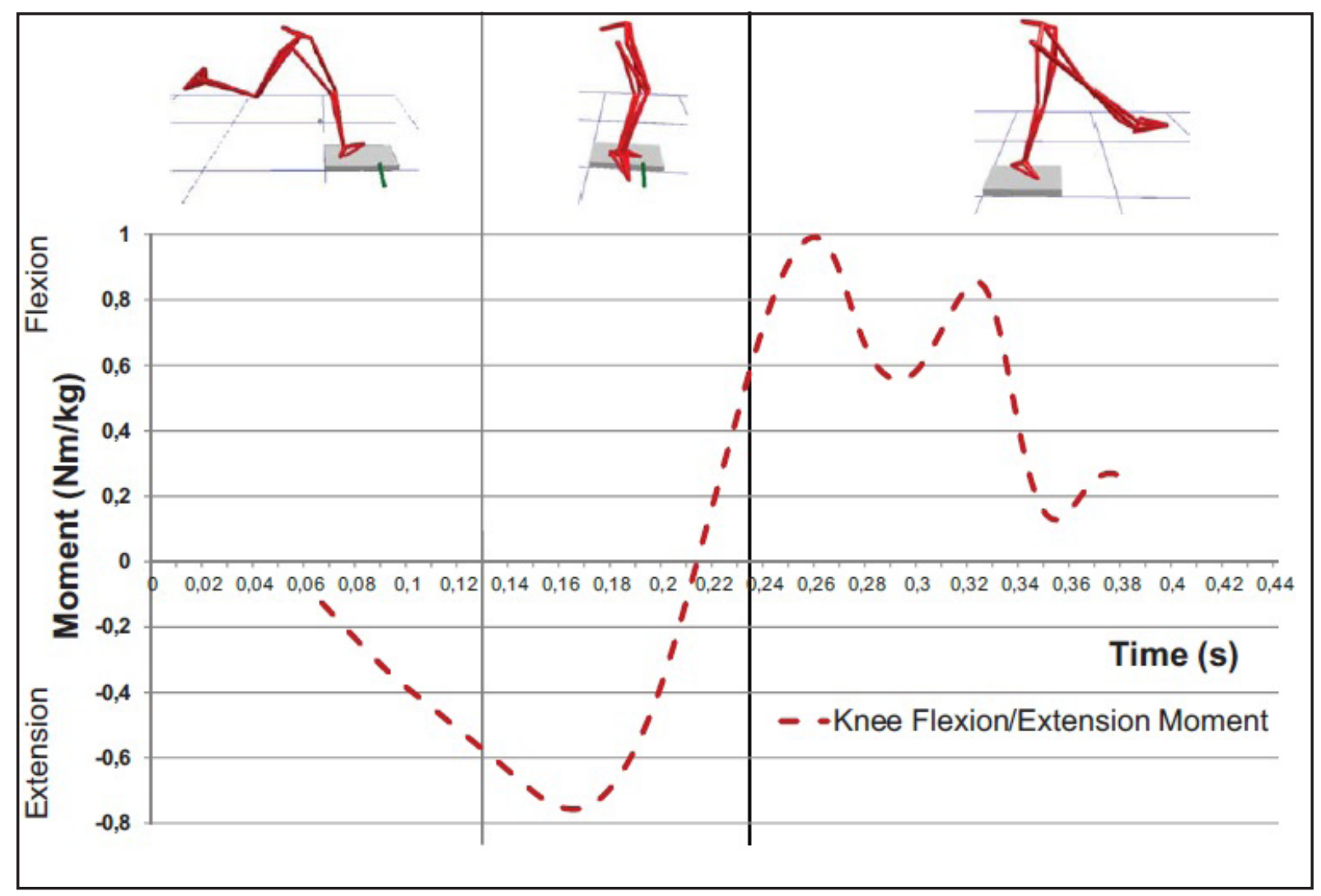

Figure 6. Variation of instep knee flexion/extension moment over time.

\begin{tabular}{|c|c|c|c|c|c|c|}
\hline & \multicolumn{3}{|c|}{ Moments at Hip (Nm/kg) } & \multicolumn{2}{c|}{ Moments at Knee: Kicking (Nm/kg) } \\
\cline { 2 - 7 } & $\begin{array}{c}\text { Peak flexion } \\
\text { moment }\end{array}$ & T3 & $\begin{array}{c}\text { Peak extension } \\
\text { moment }\end{array}$ & $\begin{array}{c}\text { Peak extension } \\
\text { moment }\end{array}$ & T3 & $\begin{array}{c}\text { Peak Flexion } \\
\text { moment }\end{array}$ \\
\hline Injured & $-3.03 \pm 0.13$ & $0.70 \pm 0.49$ & $2.28 \pm 0.66$ & $-0.82 \pm 0.14$ & $0.68 \pm 0.10$ & $0.92 \pm 0.10$ \\
\hline Un-injured & $-2.51 \pm 0.36$ & $0.87 \pm 0.37$ & $2.09 \pm 0.60$ & $-0.84 \pm 0.14$ & $0.73 \pm 0.19$ & $1.04 \pm 0.14$ \\
\hline Total & $-2.63 \pm 0.39$ & $0.83 \pm 0.39$ & $2.13 \pm 0.59$ & $-0.84 \pm 0.14$ & $0.72 \pm 0.17$ & $1.01 \pm 0.14$ \\
\hline Significance & 0.01 & 0.21 & 0.37 & 0.45 & 0.37 & 0.04 \\
\hline Abs(r) & 0.60 & 0.19 & 0.08 & 0.03 & 0.08 & 0.41 \\
\hline
\end{tabular}

Table 5. Kinetic variables during the instep kick.

\begin{tabular}{|c|c|c|c|c|c|c|}
\hline & \multicolumn{3}{|c|}{ Moments at Hip (Nm/kg) } & \multicolumn{2}{c|}{ Moments at Knee: Kicking (Nm/kg) } \\
\cline { 2 - 7 } & $\begin{array}{c}\text { Peak flexion } \\
\text { moment }\end{array}$ & T3 & $\begin{array}{c}\text { Peak extension } \\
\text { moment }\end{array}$ & $\begin{array}{c}\text { Peak extension } \\
\text { moment }\end{array}$ & T3 & $\begin{array}{c}\text { Peak Flexion } \\
\text { moment }\end{array}$ \\
\hline Injured & $-2.84 \pm 0.23$ & $1.15 \pm 0.16$ & $1.48 \pm 0.24$ & $-0.80 \pm 0.03$ & $0.61 \pm 0.12$ & $0.80 \pm 0.16$ \\
\hline Un-injured & $-2.48 \pm 0.32$ & $1.15 \pm 0.43$ & $1.42 \pm 0.46$ & $-0.79 \pm 0.17$ & $0.64 \pm 0.17$ & $0.77 \pm 0.21$ \\
\hline Total & $-2.57 \pm 0.33$ & $1.15 \pm 0.38$ & $1.44 \pm 0.41$ & $-0.79 \pm 0.14$ & $0.63 \pm 0.16$ & $0.78 \pm 0.20$ \\
\hline Significance & 0.03 & 0.41 & 0.39 & 0.45 & 0.25 & 0.45 \\
\hline Abs(r) & 0.44 & 0.05 & 0.07 & 0.03 & 0.16 & 0.03 \\
\hline
\end{tabular}

Table 6. Kinetic variables during the side-foot kick. 
It was determined that the values for the hip flexion moment at MHE was significantly greater for the injured group than the not-injured group in both the types of kicks $(Z=2.49, p=0.006$ for the instep kick and $Z=1.83, p=0.033$ for the sidefoot kick). No significant variables were observed between the injured and un-injured group for the values at the other instances $(p>0.05)$.

\section{Ground reaction forces}

The maximum ground reaction forces for the instep and side-foot kicks are shown in Table 7. The difference between the players having a previous history of hamstring injury those who did not was found to be not significant ( $p>0.05$ ).

\section{Isokinetics}

The H:Q ratios of the participants in the dominant leg at $60^{\circ} / \mathrm{s}$ and $120^{\circ} / \mathrm{s}$ are shown in Table 8 . There was no statistically significant difference found between the two groups of players. $(p>0.05)$

\section{Discussion}

\section{Kinematics}

The instep ball velocities were similar to those reported $(22.0-35.1 \mathrm{~m} / \mathrm{s})$ in other researches carried out with highly skilled players as in this study $[1,16,18]$. The side-foot velocities were however found to be slightly higher than that reported by Kawamoto et al [11] and Nunome et al [18], $21.4 \mathrm{~m} / \mathrm{s}$ for and $23.4 \mathrm{~m} / \mathrm{s}$ respectively. High school soccer players participated in the study by Nunome et al [18], while professionals took part here. Kawamoto et al [11] on the other hand had instructed their participants to kick the ball along the ground, while no such restriction was imposed in this study.

The hip flexion/extension angles and the corresponding angular velocities were similar to the values previously published in literature [16]. The hip was initially extended during the back swing phase, and in the leg acceleration phase the hip began to flex, which reduced at ball impact due to the decrease in angular velocity, as reported [16].

The pattern of knee flexion and extension is similar to that reported in literature with the extension velocity being maximized in the leg acceleration phase near ball impact (for the instep kick) and the maximum knee velocity was 1541.26 $\% / \mathrm{s}$, this being within the range stated previously $(859.44-1718.87 \%$ s) [12].

The phases of kicking were found to be similar for the injured and not-injured group except for the follow through in the instep kick. The players with a previous history of hamstring were found

\begin{tabular}{|c|c|c|c|c|c|c|}
\hline \multirow{2}{*}{} & \multicolumn{3}{|c|}{ Instep Kick (N/kg) } & \multicolumn{3}{c|}{ Side-foot Kick (N/kg) } \\
\cline { 2 - 7 } & $\mathbf{X}$ & $\mathbf{Y}$ & $\mathbf{Z}$ & $\mathbf{X}$ & $\mathrm{Y}$ & $\mathrm{Z}$ \\
\hline Injured & $-11.08 \pm 4.54$ & $4.18 \pm 12.25$ & $33.26 \pm 7.99$ & $-7.81 \pm 6.93$ & $0.40 \pm 9.78$ & $29.64 \pm 8.69$ \\
\hline Un-injured & $-8.20 \pm 3.68$ & $4.08 \pm 9.47$ & $29.13 \pm 2.94$ & $-5.78 \pm 3.64$ & $2.68 \pm 7.81$ & $26.03 \pm 3.20$ \\
\hline Total & $-8.88 \pm 3.95$ & $4.11 \pm 9.77$ & $30.10 \pm 4.66$ & $-6.26 \pm 4.44$ & $2.14 \pm 8.04$ & $26.88 \pm 4.93$ \\
\hline Significance & 0.13 & 0.37 & 0.29 & 0.33 & 0.29 & 0.41 \\
\hline Abs(r) & 0.27 & 0.08 & 0.14 & 0.11 & 0.14 & 0.05 \\
\hline
\end{tabular}

Table 7. Ground reaction forces during the instep and side-foot kicks.

\begin{tabular}{|c|c|c|}
\hline & Ratio at 60\%/s & Ratio at 120\%/s \\
\hline Injured & $0.77 \pm 0.04$ & $0.83 \pm 0.05$ \\
\hline Un-injured & $0.80 \pm 0.11$ & $0.88 \pm 0.13$ \\
\hline Total & $0.79 \pm 0.10$ & $0.87 \pm 0.12$ \\
\hline Significance & 0.30 & 0.30 \\
\hline Abs(r) & 0.21 & 0.21 \\
\hline
\end{tabular}

Table 8. Traditional H:Q isokinetic ratios in the kicking limb. 
to take a significantly larger amount of time to complete the follow through, 0.18 seconds $(40.6 \%$ of the entire kicking cycle) as compared to 0.15 seconds (32.17\% of the entire kicking cycle). During the follow through, the knee and hip undergo movements similar to those in the later part of the swing phase while sprinting. In sprinting, the rapid change from eccentric to concentric behaviour lengthens hamstring muscle fibres, making them more susceptible to injury due to the biomechanical loads placed on the muscles [4, 22]. With the movements in soccer being similar, there might be a poor activation of previously injured hamstring muscles, which are known to be very active in this phase. Another possibility is that this could be an automatic prevention mechanism to prevent re-injury which delays the follow through phase, therefore decreasing the loads on the muscles in previously injured limbs.

\section{Kinetics}

In the backswing phase, the maximum flexion moment of the hip for both the kicks was significantly greater for players with a previous injury history in the hamstrings than those without (3.03 $\mathrm{Nm} / \mathrm{kg}$ (injured) against $2.51 \mathrm{Nm} / \mathrm{kg}$ (un-injured) for instep; $2.84 \mathrm{Nm} / \mathrm{kg}$ (injured) against $2.48 \mathrm{Nm} /$ $\mathrm{kg}$ (un-injured) for side-foot. As the hamstrings are a biarticular muscle group that behave as flexors of the knee and extensors of the hip, we believe that this could be a prevention mechanism to reduce the angle of hip extension and knee flexion at the end of the back-swing phase, as evident from the relatively shorter backswing phase in the injured group, $23.30 \%$ and $22.62 \%$ of the total movement, as compared to $25.40 \%$ and $24.40 \%$ of the total movement in the un-injured group for the instep and side-foot kick respectively (Tables 3 and 4).

In the leg acceleration phase the hip experienced an extension moment although it was undergoing flexion, and the knee experienced a flexion moment although it was extending. This concurs with previous studies and is described as the "soccer paradox" [2]. It has been suggested by Lees et al [16] that sources other than muscle moments are responsible for this paradox, alluding to motion-dependent moment being in play. Similar to the result of Nunome et al [19], a backward moment was observed prior to ball impact.

\section{Ground reaction forces}

The ground reaction forces calculated in this study fell within the range of those reported in the previous studies in the antero-posterior (5.4-9.12
$\mathrm{N} / \mathrm{kg}$ ) and the lateral direction (3.82-5.79 N/kg) $[13,21]$. However the forces in the vertical direction $(30.10 \mathrm{~N} / \mathrm{kg}$ for instep and $26.89 \mathrm{~N} / \mathrm{kg}$ for the side-foot) were found to be more than that reported in literature $(20.3-23.74 \mathrm{~N} / \mathrm{kg})$. This could be due to the participation of amateur players in the previous studies, while professional players took part in this study.

\section{Isokinetics}

Many clinicians have used the hamstring to quadriceps ratio ( $\mathrm{H}: \mathrm{Q}$ ratio) as a means of predicting injury with a value greater than 0.6 stated as being suitable for most athletes [25]. A low angular speed of $60 \%$ s was selected as it permits to develop strength close to the maximal concentric strength of the subjects [24], faster speeds are thought to be closer to the speed of muscle contraction during sporting activity [20].

The values of the traditional ratio found in this study were $(0.77$ and 0.80 for the injured and uninjured limbs at $60 \%$ s; and 0.83 and 0.88 for the injured and un-injured limbs at $120 \%$ s) found to be within the range of previous studies [15, 20, $24,25]$. Also consistent with most of these studies $[15,24,25]$, there was no significant difference found between the injured and the un-injured subjects, however this was different from the findings of O'Sullivan et al [20]. Their study was done in Gaelic football while professional football players participated in this study.

It could be argued that the absence of eccentric measurements in this study was a limitation; however concentric testing is safer [20]. The amount of muscle soreness associated with eccentric muscle testing may in fact reduce subject compliance and hinder the ability to perform maximal contractions, particularly in subjects who have been previously injured [20].

\section{Conclusions}

In the study, a new procedure for evaluating the effect of hamstring injuries on the kicking skill in soccer has been proposed using the principles of inverse dynamics. The tests in the laboratory evaluated kinematic and kinetic variables of the dominant limb with the professional soccer players uninhibitedly performing the most common action in the sport, kicking. The kicking motion captured at a high sampling rate of $500 \mathrm{~Hz}$ gave some interesting results regarding the differences between the previously injured and uninjured limbs. Significant differences were observed in the time taken 
for the follow through during the instep kick, and the maximum hip flexion moment during the instep and side-foot kicks while comparing kicks across previously injured and un-injured limbs. However, while comparing these results with that of the isokinetic tests, no significant differences were obtained between previously injured and uninjured limbs in the traditional H:Q strength ratio. This might indicate that there are certain differences which may be difficult to elicit through traditional methods of testing of hamstring injuries, probably due to the players being in a sedentary position, and this novel method might be a good alternative to assess the effect of hamstring injuries in soccer players.

Since this study was retrospective in nature, it would be difficult to identify the cause of the injury through these results. Nevertheless, this work could be used as the foundation for further prospective studies and the evaluation of these biomechanical factors during the rehabilitation of injured players to get them back to their best.

\section{Acknowledgements}

We would like to express our gratitude to Dr. Nestor Pérez Mallada of the "San Juan de Dios" School of Nursing and Physiotherapy at Universidad Pontificia de Comillas, Madrid for allowing us to carry out the isokinetic testing at his laboratory and for his advice while carrying out the same.

The research was mainly carried out at the Sports Biomechanics Laboratory of the Faculty of Physical Activity and Sport Sciences at the Technical University of Madrid.

\section{References}

1. Andersen TB, Dorge HC. The influence of speed of approach and accuracy constraint on the maximal speed of the ball in soccer kicking. Scand J Med and Sc Sports 2011;21(1): 79-84.

2. Barfield WR, Kirkendall DT, Yu B. Kinematic instep kicking differences between elite female and male soccer players. J Sports Sc and Med 2002; 1: 72-79.

3. BTE Technologies. PRIMUSRS User Manual. Maryland 2002.

4. Chumanov ES, Heiderscheit BC, Thelen DG. Hamstring Musculotendon Dynamics during Stance and Swing Phases of High-Speed Running. Med and Sc Sports and Exercise 2011; 43(3): 525-532.

5. Davis III RB, Ounpuu S, Tyburski D, Gage, JR. A gait analysis data collection and reduction technique. Hum Mov Sc 1991; 10: 575-587.
6. De Leva $\mathbf{P}$. Adjustments to ZatsiorskySeluyanov's segment inertia parameters. J Biomech 1996; 29(9): 1223-1330.

7. Ebben WP. Hamstring Activation During Lower Body Resistance Training Exercises. Intl J Sports Phys and Perf 2009; 4: 84-96.

8. Ekstrand J, Hägglund M, Waldén M. Epidemiology of Muscle Injuries in Professional Football. Am J Sports Med 2011; 39(6): 1226-1232.

9. Foreman TK, Addy T, Baker S, Burns J, Hill N, Madden T. Prospective studies into the causation of hamstring injuries in sport: A systematic review. Physical Therapy in Sport 2006; 7: 101109.

10. Greig M, Siegler JC. Soccer Specific Fatigue and Eccentric Hamstring Muscle Strength. J Ath Training 2009; 44(2): 180-184.

11. Kawamoto R, Miyagi O, Ohashi J, Fukashiro S. Kinetic comparison of a side-foot soccer kick between experienced and inexperienced players. Sports Biomech 2007; 6(2): 187-198.

12. Kellis E, Katis A. Biomechanical characteristics and determinants of instep soccer kick. J Sports Sc and Med 2007; 6: 154-165.

13. Kellis E, Katis A, Gissis I. Knee Biomechanics of the Support Leg in Soccer Kicks From Three Angles of Approach. Med and Sc in Sports and Exercise 2004; 36: 1017-1028.

14. Knudson D, Bahamonde R. Effect of endpoint conditions on position and velocity near impact in tennis. J Sports Sc 2001; 19(11): 839-844.

15. Lee MJC, Reid SL, Elliott BC, Lloyd DG. Running Biomechanics and Lower Limb Strength Associated with Prior Hamstring Injury. Med and Sc in Sports and Exercise 2009; 41(10): 1942-1951.

16. Lees A, Asai T, Andersen TB, Nunome H, Sterzing $\mathbf{T}$. The biomechanics of kicking in soccer: A review. J of Sports Sc 2010; 28(8): 805-817.

17. Mallo J, González P, Veiga S, Navarro E. Injury incidence in a Spanish sub-elite professional football team: A prospective study during four consecutive seasons, J Sports Sc and Med 2011; 10(4): 731-736.

18. Nunome H, Asai T, Ikegami Y, Sakurai S. Three-dimensional kinetic analysis of side-foot and instep soccer kicks. Med and Sc in Sports and Exercise 2002; 34(12): 2028-2036.

19. Nunome H, Ikegami Y, Kozakai R, Apriantono T, Sano S. Segmental dynamics of soccer instep kicking with the preferred and non-preferred leg. J of Sports Sc 2006; 24(5): 529-541.

20. O'Sullivan $\mathbf{K}$, O'Ceallaigh $\mathbf{B}$, O'Connell $\mathbf{K}$, Shafat A. The relationship between previous hamstring injury and the concentric isokinetic knee muscle strength of irish gaelic footballers. BMC Musculoskeletal Disorders, 2008; 9(30).

21. Orloff H, Sumida B, Chow J, Habibi L, Fujino A, Kramer B. Ground Reaction Forces and Kinematics of Plant Leg Position During Instep 
Kicking in Male and Female Collegiate Soccer Players. Sports Biomech 2008; 7(2): 238-247.

22. Petersen $\mathbf{J}$, Holmich $\mathbf{P}$. Evidence based prevention of hamstring injuries in sport. $\mathrm{Br} \mathrm{J}$ of Sports Med 2005; 39: 319-323.

23. Tebutt P, Wood J, King M. The Vicon Manual. Oxford 2002

24. Tourny-Chollet C, Leroy D, Leger H, BeuretBlanquart F. Isokinetic knee muscle strength of soccer players according to their position. Isokinetics and Exercise Sc 2000; 8: 187-193.

25. Wright J, Ball N, Wood L. Fatigue, H/Q ratios and muscle coactivation in recreational football players. Isokinetics and Exercise Sc 2009; 17: 161-167. 